\title{
Musculoskeletal Imaging
}

Philip G. Conaghan, Philip J. O'Connor, and David A. Isenberg, editors; Oxford: Oxford University Press. 455 pages. \$US85.00

This pocketbook $(18 \times 10 \mathrm{~cm})$ is a 455 -page guide that combines clinical descriptions of regional syndromes with a superficial list of radiological findings. There are 16 pages on inflammatory arthritis and 43 pages on autoimmune rheumatic diseases. The copious illustrations are minimal in size and detail, 2 or 3 or sometimes 4 on a page. The text deals primarily with which radiological modality will show the lesion best and what it will show. This is a quick reference manual that may have a role in outpatient clinics. Although 12 of the section authors are radiologists and 12 are rheumatologists, it seems to me that the manual has a decided slant toward medical orthopedics.

ARTHUR A. BOOKMAN, MD, FRCPC, University Health Network, Toronto Western Hospital, Toronto, Ontario, Canada

J Rheumatol 2011;38:4; doi:10.3899/jrheum.101384 